\title{
Mundos invisíveis: Um faz de conta que dialoga com diversas realidades
}

William Scheidegger Moreira ${ }^{1}$

...De uma América a outra consigo passar num segundo, Giro um simples compasso e num círculo eu faço o mundo

Um menino caminha e caminhando chega no muro E ali logo em frente, a esperar pela gente, o futuro está E o futuro é uma astronave que tentamos pilotar, Não tem tempo nem piedade, nem tem hora de chegar Sem pedir licença muda nossa vida, depois convida a rir ou chorar...

Toquinho, 1996

\section{Resumo}

O presente artigo trata de um relato de experiência realizado a partir de observações feitas em uma escola regular, na zona norte do Rio de Janeiro. Aqui, serão oferecidos subsídios para que possamos refletir um pouco mais a respeito da importância do brincar criativo no desenvolvimento infantil. A excessiva influência midiática que crianças vêm sofrendo diariamente por conta de demasiadas exposições à mídia de tela e a intersecção entre tais influências e o brincar imaginativo, pautando as dificuldades que algumas crianças vêm apresentando em relação ao brincar criativo por conta de tais exposições que, também serão alvo para reflexão. Muitas vezes, tais exposições terminam por criar demagogias específicas nas brincadeiras livres de nossas crianças, comprometendo a criatividade.

Palavras-chave: Criatividade, Mídia, Escola, Brincar e Consumo.

\begin{abstract}
:
This present article talks about a monitoring experience made in a regular school, in the North Zone of Rio de Janeiro. In this paper, some aids will be offered to make an analysis of the importance of creative plays in the development of the kids. The excessive influence of the media that kids have been suffering daily because of the intensive exposition to the video medias, such as televisions, and the intersection between these influences and the imaginative play, guiding the difficulties that some kids have been presenting in its creative plays because those expositions that also will
\end{abstract}

\footnotetext{
${ }^{1}$ Graduado em Pedagogia pela Universidade do Estado do Rio de Janeiro. Email: < williamscheidegger@hotmail.com>

Criar Educação, Criciúma, v. 8, no1, jan/jul 2019.- PPGE - UNESC
} 
be aims of reflection. Many times, those expositions tend to create specifics demagogies in the plays of our kids, compromising the creativity.

Key-words: Criativity. Media, School, Play and consumption.

\section{Introdução:}

A composição de Toquinho nos remete a outros mundos, a outros espaços repletos de imaginações e desejos inerentes à infância. Os versos cantados pelo compositor apresentam vasta capacidade dialógica entre nosso mundo interno e externo ${ }^{2}$, criando e recriando cenas, situações, contextos e histórias que nos parecem tão reais quanto não são. O canto em questão mostra-se em tamanha profundidade por que nos toca na instância mais íntima de nosso ser: na fantasia.

E o que seria fantasia? Arrisco-me a crer que fantasia é, de fato, tudo aquilo que criamos e idealizamos de forma imaginativa ao longo de nossa história, e é o principal caminho que nos liga ao faz de conta, ao brincar. Segundo Linn (2010, p.27) "o faz de conta das crianças tem raízes na experiência única que elas têm com pessoas e eventos", ou seja, pode-se pensar que o faz de conta trata de situações subjetivamente elaboradas por nós, advindas da objetividade que está intimamente ligada a desejos, vivências e situações diversas que nós passamos ou desejamos passar.

O fazer de conta, presente em todas as fases da vida humana, sem dúvidas, apresenta-se de maneira mais enfática e perceptível nos primeiros anos de vida do ser humano, quando este ainda é criança. Geralmente, acredita-se que o faz de conta é característica única e própria da infância, porém, há quem defenda a ideia de que ele permanece em nossa vida até o fim desta. Se essa defesa posta for mesmo um fato, creio que possamos nos perguntar em que momento, então, o faz de conta encontra-se presente na vida adulta, se é que tais momentos podem ser delimitados. Rosa (2001) nos oferta alguns questionamentos precedidos das seguintes colocações:

\footnotetext{
${ }^{2}$ Winnicott, 1971.

Criar Educação, Criciúma, v. 8, no1, jan/jul 2019.- PPGE - UNESC
} 
[...] qual o adulto que não se diverte ao entrar numa "casa maluca"- dessas que existem em parques de diversão-, onde o que há para ser visto desafia frontalmente as leis da lógica? Ou que, diante de espelhos que distorcem o refletido, mostra uma cabeça muito cumprida num corpo muito pequeno e vice e versa, não irrompe numa incontrolável gargalhada? [...] sugiro que o que exista aí é a ilusão do fato de transgredir, no sentido de ultrapassar as barreiras impostas pelo real, e viver uma experiência onde o desejo, ironizando a pura objetividade, abre espaço para a sua realização. (Rosa, p. 19)

À luz dos pensamentos de Rosa, pode-se observar que, para além das situações descritas como possibilidades de brincar envolvendo o faz de conta na vida adulta, existe também a atração dos adultos por tudo aquilo que envolva ilusão, pela realização daquilo que é objetivamente impossível, mas subjetivamente desejável. De acordo com Winnicott:

O que quer que se diga em relação ao brincar das crianças, aplica-se também aos adultos; apenas, a descrição torna-se mais difícil quando o material do paciente aparece principalmente em termos de comunicação verbal. Sugiro que devemos encontrar o brincar tão em evidência nas análises de adultos quanto o é no caso de nosso trabalho com crianças. Manifesta-se, por exemplo, na escolha de palavras, na inflexão de voz e, na verdade, no senso de humor. (Winnicott, p. 61)

Atualmente, é legítimo admitirmos que muito se debate no campo da Educação a respeito da importância do brincar, mas o que trago como questionamentos é: Por que tanto se discute a respeito do brincar no campo Educacional? Há relação entre brincar e aprender? Qual a importância do brincar livremente no desenvolver humano? Quais os ganhos obtidos ao indivíduo que goza de liberdade para brincar e usufruir de seu faz de conta? E qual a importância da experimentação de determinados sentimentos, situações, reações e/ou resolução de problemas através do faz de conta quando se é criança? É baseado nestes questionamentos que me proponho a relatar e discutir, sem a pretensão de responder tais perguntas e sim de refletir sobre as mesmas, uma experiência vivida por mim. Experiência esta que apoiou-se em profundas observações do brincar de um grupo de meninas com faixa etária de 5 aos 8 anos de idade em uma escola situada da zona norte do Rio de Janeiro. O grupo de 
crianças era composto por seis meninas que, aqui, designarei como Júlia de 5 anos, Clara de 8 anos, Bia de 6 anos, Lia de 5 anos, Isadora de 6 anos e Tati de 5 anos ${ }^{3}$.

\section{Um faz de conta que acontece}

Como todos os outros dias letivos, após a realização das tarefas escolares e do lanche da tarde, os alunos e alunas foram levados para a área externa à sala de aula, onde a turma do grupo $4^{4}$ brinca junto com a turma do primeiro ano do ensino fundamental. Lia, Isadora e Tati fazem parte do grupo 4, enquanto Clara, Bia e Júlia pertencem ao primeiro ano do ensino fundamental.

A escola em que as observações foram feitas, que aqui designarei como "Escola do Desenvolvimento" 5 , não oferece brinquedos de caráter midiático aos alunos. Ao invés disso, oferece objetos e utensílios do dia a dia com a finalidade de deixar os alunos e alunas a vontade para explorar a imaginação e criar suas próprias brincadeiras. Para Vygotsky:

No início da idade pré-escolar, quando surgem os desejos que não podem ser imediatamente satisfeitos ou esquecidos, e permanece ainda a característica do estágio precedente de uma tendência para a satisfação imediata desses desejos, o comportamento da criança muda. Para resolver essa tensão, a criança de idade pré-escolar envolve-se em um mundo ilusório e imaginário onde os desejos não realizáveis podem ser realizados, e esse mundo é o que chamamos de brinquedo. (Idem p.122)

Segundo as concepções do autor, brinquedo pode ser entendido, se não, como 0 ato e efeito de brincar. Desprendido de caráteres específicos relacionados a produtos midiáticos, frequentemente propagandeados pelo mercado, Vygotsky nos proporciona uma visão mais elaborada sobre brinquedo e sua funcionalidade onde,

\footnotetext{
${ }^{3} \mathrm{O}$ verdadeiro nome das alunas foram preservados por questões éticas.

${ }^{4}$ Denominação dada ao grupo de crianças da educação infantil que é composto de alunos de 4 a 5 anos de idade.

${ }^{5} \mathrm{O}$ nome da escola foi preservado por questões éticas.
}

Criar Educação, Criciúma, v. 8, no1, jan/jul 2019.- PPGE - UNESC 
não se atendo a objetos e sim a ação dos sujeitos, debate sobre a tão importante funcionalidade desta prática.

Dentre os objetos da referida escola, que são oferecidos às crianças na hora do recreio, está uma cesta repleta de cangas de praia que as meninas adoram. Logo ao chegarem à área verde ${ }^{6}$, as meninas solicitaram a tão adorada cesta com cangas para iniciarem suas tão esperadas brincadeiras diárias.

A cesta solicitada pelas alunas Ihes foi dada. Em questão de minutos, aquelas cangas que encontravam-se, até então, abandonadas dentro da cesta, ganharam vida e transformaram-se em belos e exuberantes vestidos de princesas que, por sua vez, habitavam um belíssimo reino encantado. A área verde então transformou-se em um castelo com masmorras, trono real, jardins, cachoeiras, animais e muitos quartos.

As meninas que ali brincavam, transformaram-se em princesa, rainha, guardas reais e servas costureiras e faxineiras.

Júlia transformou-se de imediato em uma rainha e passou a ocupar um belo e ilustre trono, no caso, uma cadeira forrada com cangas coloridas dignas de uma rainha. Bia, melhor amiga de Júlia, ocupou então o lugar de princesa e passou a sentar-se num trono ao lado da rainha Júlia. O trono da princesa Bia não era enfeitado como o da rainha Júlia, mas estava bem próximo à majestade e isso foi suficiente para a princesa.

Isadora e Tati ocuparam o cargo de guarda real. Elas eram responsáveis por seguir as ordens da rainha e proteger o castelo dos invasores a todo custo. Lia e Clara assumiram o papel de criadas, responsáveis por limpar a casa, fazer as roupas reais e cuidar dos animais do castelo.

Ao definirem os papeis, iniciou-se a trama. Ao assumir o trono, a rainha logo deu suas primeiras ordens às criadas:

Júlia: Rápido, criadas! Preciso de um vestido para o baile! Hoje a noite terá uma festa no reino! O príncipe escolherá sua noiva e preciso estar linda para dançar! Clara e Lia: Sim, majestade!

\footnotetext{
${ }^{6}$ Espaço livre direcionado ao brincar criativo dos alunos.

Criar Educação, Criciúma, v. 8, no1, jan/jul 2019.- PPGE - UNESC
} 
Júlia: Guardas, vigiem a porta e não deixem ninguém entrar no castelo! O nosso reino é lindo, não pode ser invadido!

Tati e Isadora: Sim, majestade!

Ao dar as ordens às guardas do castelo, a rainha Júlia percebeu então que a guarda Isadora gozava de algo que ela não tinha: Maquiagem azul nos olhos.

Neste dia, Isadora chegou à escola maquiada com sombra azul nos olhos que realçavam ainda mais seus olhos de cor azul como o céu. De fato, aquela maquiagem não era digna de uma guarda real e sim de uma rainha. Ao perceber a pintura no rosto da guarda real, a rainha Júlia a questionou:

Júlia: Guarda Isadora, o que é isso nos seus olhos? É maquiagem? Isadora: Sim, majestade! Minha mãe passou em mim! Júlia: Me dê toda a sua maquiagem! Eu quero ela pra mim! Eu sou a rainha!

Isadora então, rindo histericamente, respondeu:

"Não! É minha! Ela está nos meus olhos!"

Os risos e a resposta de Isadora levaram a rainha ao ódio mortal! E com gritos histéricos de fúria ela ordenou às servas e a outra guarda do castelo:

"Peguem ela e arranquem os olhos dela! Peguem ela agora e levem para o fundo do castelo com os monstros! Eu quero essa maquiagem pra mim! Eu sou a rainha!"

As criadas, a princesa e a outra guarda real, obedientes, correm por todo o castelo atrás de Isadora que insistia em fugir. Ao ser capturada, a rainha Júlia se dirigiu até ela e passou as mãos em seus olhos afim de retirar sua pintura e aplica-la aos seus próprios olhos. O processo se repetiu muitas outras vezes e quando a rainha julgou ser suficiente, Isadora foi então deixada para trás e sua personagem, simplesmente é apagada da história. As meninas já não respondiam mais às suas 
solicitações na brincadeira, até que Isadora cansou-se de ser ignorada e foi em busca de outra brincadeira, com outro grupo de alunos.

$\mathrm{Na}$ volta ao trono, andando pelo jardim do castelo, a princesa Bia tropeçou e caiu em um rio, afogando-se e desmaiando, esperando ser salva. A rainha então ordenou à criada Clara que a salvasse. Obediente, Clara salta no rio com toda a coragem e consegue retirar Bia, que já estava morta. A rainha Júlia ajoelha-se e com movimentos que simbolizavam magia, ressuscita a princesa com seu poder da cura.

Ao ressuscitar a princesa Bia, as meninas escutam gritos de socorro. Era Clara, a serva, que havia caído no rio e estava se afogando, prestes a morrer. Clara suplicava por ajuda, agonizando, porém, a rainha e suas servas nada fizeram. Clara se debateu nas águas até ficar inconsciente. A rainha então levantou-se, dando seu parecer real:

"Ela é a criada, pode morrer. Já salvamos a princesa, vamos para o castelo."

Sozinha, Clara voltou a consciência e saiu do rio, dirigindo-se ao castelo junto às demais companheiras.

Algumas ordens de confecção de roupa foram dadas e alguns convites de bailes chegaram ao castelo antes que a professora anunciasse o fim da hora do recreio. As cangas, então, voltaram a ser apenas panos, o castelo desapareceu dando lugar à área verde e as personagens voltaram a ser apenas meninas da pré-escola e do primeiro ano do ensino fundamental.

Aparentemente, tudo aquilo fora só uma brincadeira, mas possivelmente, muitas outras questões estavam ali envolvidas.

\section{A verdade por trás do faz de conta: A demagogia midiática em relação à infância}

A brincadeira narrada anteriormente pode parecer apenas história de faz de conta como muitas outras criadas por crianças ao redor do mundo. O que julgo importante ser posto em questão é a relação do brincar com a vida real e a dimensão 
que este ato atinge na construção do sujeito. Para alguns pesquisadores, o brincar representa um portal entre o mundo interno dos sujeitos e o mundo externo em que vivemos. Através do brincar, quando crianças, canalizamos desejos, questões, sentimentos e sensações subjetivas para o mundo externo afim de experimentá-los, construí-los e reconstruí-los. Cria-los e recriá-los como uma forma de interação entre o que somos e o que nos cerca, como afirma Linn:

\begin{abstract}
A brincadeira de faz de conta desabrocha na interseção entre o mundo interior de fantasia e das reflexões e o mundo exterior que existe no tempo e no espaço. Diferentemente dos devaneios e da maioria de nossas interações com outras pessoas, ela existe sem estar inteiramente no mundo interior ou exterior - mas pode dar forma aos dois. (2010, p.28)
\end{abstract}

Sob essa perspectiva, o faz de conta torna-se responsável, nos primeiros anos de vida, em manter o diálogo entre o real e o fantasioso, expondo de maneira socialmente aceitável, ou não, através de brincadeiras, tudo aquilo que os pequenos sujeitos não compreendem dentro deles mesmos.

O brincar criativo, defendido por muitos como campo a ser preservado, é visto também, por muitos, como típico, íntimo e natural da infância. Contudo, alguns alertas e observações vêm sendo feitos a respeito desta tão importante ação infantil.

A era do mundo moderno trouxe com ela a explosão excessivamente absurda da cultura de capital e, como consequência deste fator, o público infantil tem se tornado um grande alvo no que diz respeito à comercialização de produtos, criando nos pequenos, cada vez mais, uma cultura de consumo incontrolável onde o possuir vem sendo posto como parâmetro de felicidade e realização na vida das crianças.

A mídia televisiva vem contribuindo de maneira significativa no estabelecimento desta nova cultura. Crianças são expostas a telas desde muito cedo e por um tempo bem preocupante. Os desenhos animados e programas voltados ao público infantil passaram a vincular suas imagens a produtos e mercadorias que, cada vez mais, vem ocupando espaço significativo no cotidiano de nossas crianças.

A lucratividade monetária exacerbada das grandes corporações vem contribuindo para um estabelecimento cada vez maior do mercado voltado ao público Criar Educação, Criciúma, v. 8, no1, jan/jul 2019.- PPGE - UNESC 
infantil que, por consequência, terminam por constituir sujeitos compulsivamente consumistas. E para a propagação desta cultura, as corporações vêm usando cada vez mais a mídia televisiva e a internet como ferramenta fundamental neste processo. Para que tenhamos uma ideia mais ampla a respeito deste fato, trago uma pesquisa realizada por Linn constatando que:

A televisão é o veículo primário para da propaganda voltada para crianças, mas o marketing na internet está progredindo. O site norteamericano na Nickelodeon teve um rendimento de 9,6 milhões de dólares entre julho de 2004 e julho de 2005 - mais recursos publicitários do que qualquer outro site para crianças ou adultos. Quando a Kaiser Family Fundation examinou os 77 sites que as companhias de alimentos usam para atingir o público infantil, descobriu que eles receberam mais de 12,2 milhões de visitas de crianças com idades entre 2 e 11 anos no segundo semestre de 2005. (Idem, 2010, p. 49)

Ao nos depararmos com dados tão significativos, julgo interessante analisarmos as questões que pairam em torno de tais resultados. Até que ponto as influências midiáticas impactam no desenvolvimento de nossas crianças? Em que instância elas praticam o brincar criativo? Seria a influência midiática um perigo real ao faz de conta livre? Se sim, quais as correntes invisíveis impostas pela mídia em relação aos pequenos que, possivelmente, possam comprometer o seu brincar imaginário?

\section{O faz de conta em risco}

É um fato que, desde os tempos mais remotos, muitas sociedades possuem culturas que demarcam as questões relacionadas a gêneros, etnias e etc. Em muitos casos, estas construções são feitas desde muito cedo na vida dos indivíduos que a estas sociedades pertencem. De acordo com Chauí:

Com frequência ouvimos dizer: "os homens são fortes e racionais, feitos para o comando e a vida pública", donde, como consequência, outra frase: "fulana nem parece mulher. Veja como se

Criar Educação, Criciúma, v. 8, no1, jan/jul 2019.- PPGE - UNESC 
veste! Veja o emprego que arranjou!" Não é raro escutarmos que os negros são indolentes por natureza, os pobres são naturalmente violentos, os judeus são naturalmente avarentos, os árabes são naturalmente comerciantes espertos, os franceses são naturalmente interessados em sexo e os ingleses são, por natureza, fleumáticos.

Frases como estas, e muitas outras, pressupõem por um lado, que existe uma natureza humana, a mesma em todos os tempos e lugares e, por outro lado, que existe uma diferença de natureza entre homens e mulheres, pobres e ricos, negros, índios, judeus, árabes, franceses ou ingleses. Havia, assim, uma natureza humana universal diferenciada por espécies, à maneira da diferença entre várias espécies de plantas ou de animais. (Idem, 2000)

Mas, com tais declarações, talvez, um hipotético leitor se pergunte aonde queremos chegar com todas estas questões. O que se passa é que, na realidade, demarcações sociais específicas ocorrem ao nascermos onde, sem titubear, os sujeitos pertencentes a nossa sociedade projetam políticas específicas em nossos corpos como demarcações íntimas inerentes a quem nós somos ou, ao menos, a quem devemos ou deveríamos ser.

Todavia, as crianças como indivíduos pertencentes a este meio social não estão isentas destas cruéis denominações. Como poderosa aliada a estes estereótipos, está a mídia. Mídia esta que vem produzindo cada vez mais delimitações específicas do que devemos ser e o lugar social que devemos ocupar.

Neste sentido, o que de fato é relevante, trata-se das influências demagógicas midiáticas em torno da construção dos sujeitos infantis. A forma cruel como os desenhos animados e programas voltados à infância produzem e reforçam posições específicas sobre os sujeitos que a eles são expostos.

A descrição da brincadeira das meninas que trata este artigo, a priori, relata um brincar criativo e saldável, onde as meninas em questão (re)significam objetos e constroem histórias com vasta imaginação e criatividade.

É inegável que no relato descrito haja fantasia e criatividade, entretanto, se analisarmos de maneira mais minuciosa, perceberemos que, ainda que encontremos interação entre objetividade e subjetividade pautada na criatividade, tal atividade não pode ser descrita como absolutamente autônoma. As meninas transformaram-se, se não, em princesas, viviam em um castelo situado em um reino feliz, em algumas situações esperaram ser salvas e, em outras, assumiram papeis ditatórios e maléficos, Criar Educação, Criciúma, v. 8, no1, jan/jul 2019.- PPGE - UNESC 
tal qual fazem algumas rainhas e madrastas nos contos de fada, além de terem sido convidadas para bailes.

Ainda que estas meninas tenham tido espaço para desenvolver seu brincar e fazer criativo, estes foram moldados pelas influências midiáticas a qual estão expostas no dia a dia. Por mais que nada relacionado a contos de fadas e/ou princesas thes fosse ofertado naquele momento, os objetos que dispunham em seus domínios foram, de imediato, (re)significados como adornos típicos de um mundo ilustrado por adultos que desenham contos voltados ao público feminino infantil.

As meninas da brincadeira relatada anteriormente não assumiram outros papeis que não fossem aqueles que elas mesmas frequentemente assumem durante o tempo livre dedicado ao brincar. É um fato relevante a ser elucidado também que, para além da influente condução no brincar criativo destas, e possivelmente de outras meninas, possibilidades de outras vivências através do faz de conta terminam por serem excluídas, dado o único modelo apresentado pela mídia de condição de princesa como caráter de perfeição feminina.

Pensando um pouco mais além, os atuais contos envolvendo princesas trazem como problemática a não representação em pluralidade das meninas em geral. Estereótipos são cada vez mais reforçados e este fato constitui, para muitas, um cenário de dor e frustração por não se encaixarem em um modelo que também deveria pertencer a elas. Sob a luz dos pensamentos de Linn:

Quando contos de fadas se tornam megamarcas comerciais, sua profundidade e maleabilidade diminuem, como seu valor como ponto de partida para o brincar criativo. Quando os contos de fada se tornam questões visuais dos valores de outra pessoa - assistidos inúmeras vezes e vendidos associados à tiaras, joias, vestidos de baile e castelos e repletos de imagens de princesas específicas com fisionomias específicas - , eles trancam a criança em um roteiro estabelecido de brincadeiras do qual é muito difícil de desviar. A imersão da marca das Princesas Disney - com seu foco no brilho e na aquisição - excluem o brincar com os aspectos psicologicamente mais significativos das histórias, os quais acontecem antes das heroínas se tornarem princesas: temas de perda, rivalidade entre irmãs e conflitos entre pais e filhos. (Idem, 2010, p. 242)

Refletir sobre esses dilemas pode nos encaminhar para a oferta de outras possibilidades e alternativas à nossas crianças. Para que possamos lutar pela Criar Educação, Criciúma, v. 8, no1, jan/jul 2019.- PPGE - UNESC 
preservação de seu brincar criativo e salvaguardar a singularidade da brincadeira livre envolvendo a criatividade, sem que esta seja conduzida ou ditada pelo ambiente externo aos pequenos que brincam.

\section{Conclusão}

Com base em tudo o que foi relatado e discutido no presente artigo, podemos por em pauta a importância da compreensão dos efeitos midiáticos sobre nossas crianças e os danos que estes podem causar em seus fazeres imaginários.

Podemos refletir também a respeito da importância do brincar livre, criativo, e dialogar sobre os benefícios que este nos trás para toda a vida e para a vida daqueles que deste prazer podem desfrutar de maneira plena e satisfatória. Contudo, resguardar esta capacidade nas atuais crianças que, diariamente, são bombardeadas por aparatos midiáticos, transformando-se em vítimas frequentes de corporações e mercados consumidores, vem se apresentando como tarefa cada vez mais árdua na contemporaneidade.

Para nós, profissionais da educação, nos resta então procurar fazer da escola um espaço promotor deste fazer criativo. Expandindo horizontes e ampliando possibilidades para que esta área do desenvolvimento, que é tão fundamental, não termine por extinguir-se por completo.

Ainda que, dadas as circunstâncias, esta tarefa pareça impossível, cabe a cada um de nós buscar meios para a criação de oportunidades para a realização do faz de conta no cotidiano escolar. A escola é campo de desenvolvimento e produção do saber. Busquemos então a não alienação dos sujeitos dentro dos muros da escola. Procuremos então fornecer aos indivíduos, que à escola frequentem, aparatos para que possam relacionar um mundo subjetivamente particular com o externo, e não se tornem reprodutores de padrões pré-estabelecidos por aqueles que buscam apenas aquisição monetária.

\section{Referências Bibliográficas:}


LINN, S. In: Em defesa do faz de conta. 1ed. Rio de Janeiro: BestSeller, 2010. ROSA, S.S. In: Brincar, conhecer, ensinar. 2ed. São Paulo: Cortez, 2001. VYGOTSKY, L.S. in: A formação social da mente. 2ed. Rio de Janeiro: Martins Editora, 2007.

CHAUÍ, M. A cultura. In: Convite a filisofia. ed: Ática: São Paulo, 2000. WINNICOTT, D.W. In: O brincar e a realidade. 1ed. Rio de Janeiro: Imago Editora LTDA, 1971.

Recebido em setembro 2018 Aprovado em março 2019 